\title{
Reflexões sobre a tecnologia educativa: conceitos e possibilidades
}

\author{
Angela Gonçalves de Souza (SOUZA, Angela G. de) \\ Mestranda na Universidade Federal de Uberlândia - UFU \\ angelagsouza@gmail.com \\ Maria Carmen Khnychala Cunha (CUNHA, Maria Carmen K.) \\ Professora Doutora na Universidade Federal de Uberlândia - UFU \\ mcarmenk@gmail.com
}

\section{Resumo}

O uso das "novas" tecnologias para a melhoria do processo de ensino e aprendizagem é algo que já está posto. Nossos alunos utilizam, constantemente, algum tipo de tecnologia e nós, professores, precisamos conhecer um pouco mais acerca de suas possibilidades. Este artigo visa diferenciar os termos tecnologia e novas tecnologias para, em seguida, refletir acerca de seus possíveis usos na educação e, por fim, analisar o caso do uso do blog em sala de aula de língua inglesa, assim como as crenças dos participantes quanto a essa ferramenta. A Epistemologia Qualitativa foi a metodologia utilizada nesta pesquisa. Alguns problemas foram encontrados tanto pelos aprendizes quanto pela professora no uso do blog e das "novas" tecnologias como ferramentas para o ensino e aprendizagem, mas a experiência, ainda assim, foi positiva.

Palavras-chave: novas tecnologias, educação, crenças, ensino de inglês como língua estrangeira

\begin{abstract}
The use of "new" technologies to improve the teaching and learning process has already become inevitable. Our students are constantly in touch with some kind of technology, and as teachers we need to know more about the possibilities of that use. The aim of this article is to differentiate the terms technology and new technologies in order to reflect upon their uses in the classroom, as well as to analyze the case of the use of a blog in an EFL classroom and the beliefs of teacher and learners about this tool. The methodology employed in this study was Qualitative Epistemology. Although a few problems were encountered in using the blog and "new" technologies as tools for language teaching and learning, the experience was positive.
\end{abstract}

Keywords: new technologies, education, beliefs, English as a Foreign Language (EFL). 


\section{Introdução}

O escritor americano Joseph Wood Krutch (1893-1970) afirmou que "a tecnologia torna as grandes populações possíveis, e as grandes populações tornam a tecnologia indispensável" (apud BUCHSBAUM; BUCHSBAUM, 2006, p. 238). Se a tecnologia é indispensável no mundo de hoje, especialmente as novas tecnologias, torna-se, pois, indispensável também refletirmos sobre seu uso e seu papel na educação. O objetivo principal deste trabalho é refletir sobre como a tecnologia pode contribuir para o processo de ensino e aprendizagem e, em seguida, tecer algumas considerações acerca de uma experiência com a utilização de um blog em um contexto de ensino e aprendizagem de língua inglesa. Antes disso, no entanto, cabe um esclarecimento: " $\mathrm{O}$ que é tecnologia e o que são novas tecnologias?” Assim, a primeira parte deste trabalho tratará dessa distinção.

\section{Tecnologia vs novas tecnologias}

O senso comum, geralmente, pensa em tecnologia como algo ligado ao mundo dos computadores, da informática. No entanto, essa idéia é muito restrita. Martinez (2006) descreve a tecnologia não como um mero conhecimento técnico que o homem acumula, mas como a capacidade e a arte de estudar, projetar, produzir ou reutilizar técnicas, equipamentos e objetos. Para ele, essa produção ou reutilização pode servir a usos diferentes e inesperados, porém a tecnologia deve ser capaz de:

[...] criar, transformar e modificar materiais, recursos, insumos ou a natureza como um todo, o entorno social e o próprio homem, em virtude do engendramento de novas ações, aportes, suportes, especialmente se resultarem em modificações de todos os envolvidos (base técnica e relações humanas) pelos novos usos e utilidades. (MARTINEZ, 2006, p. 2)

A afirmação de Martinez é interessante por definir tecnologia como um "saberfazer”, ou seja, é um conhecimento que envolve mudanças não apenas em materiais e coisas, mas, sobretudo, na sociedade e mesmo no homem e em suas relações com o mundo. Visando a uma mesma finalidade, é possível proporcionar um resultado melhor, a partir de usos diferentes e inesperados de uma mesma tecnologia. O uso que o homem faz de uma determinada tecnologia é o que possibilita mudanças que podem ter impacto em todos os envolvidos. Tal questão é relevante para a construção de um projeto pedagógico tecnológico de qualidade, pois deverá envolver não apenas o professor, mas também a direção, a coordenação, a escola como um todo e, principalmente, o aluno. A tecnologia na sala de aula não deve ser apenas um suporte para facilitar a vida do professor, no sentido de, por exemplo, substituir o quadro por apresentações em Powerpoint. Conforme Nunes (2007),

o uso das novas tecnologias na educação [...] deve ser feito com cuidado para que a tecnologia [...] não se torne para o professor apenas mais uma maneira de 'enfeitar' as suas aulas, mas sim uma maneira de desenvolver habilidades e competências que serão úteis para os alunos em qualquer situação da vida. (NUNES, 2007, p. 2) 
É nesse sentido que se discute a necessidade de uma mudança de paradigma no contexto de ensino e aprendizagem de modo que o processo esteja voltado para a construção de conhecimento de fato, e não acúmulo de informações. O que se deseja é um conhecimento que vise a abordar as competências necessárias para a sociedade atual, as quais, segundo Gardner (2007, p. 12-13), envolvem a "mente disciplinada”, a "sintetizadora", a "criadora", a "respeitosa" e a mente "ética".

De acordo com Linard (1996), tecnologia é um "conjunto de discursos, práticas, valores e efeitos sociais ligados a uma técnica particular num campo particular" (LINARD, 1996, apud BELLONI, 2006, p. 53). Assim, o giz, o quadro negro e o livro são tecnologias, porém antigas. Chaves (1999) ratifica a definição anterior e afirma que a tecnologia se refere a tudo o que foi inventado pelo homem com o objetivo de simplificar o trabalho, e, ao mesmo tempo, aprimorar as relações entre os indivíduos.

A tecnologia hoje, com a World Wide Web, e suas comunidades virtuais, seus inúmeros sites de relacionamento, seus chat rooms, está bastante relacionada às relações interpessoais. Além disso, conforme Chaves (1999), ela é capaz de expandir nossa capacidade sensorial, motora e mental, o que podemos observar claramente nos jovens da "geração Internet", que possuem de fato grande habilidade dos sentidos e de coordenação motora. A Internet, ao disponibilizar tantas informações, mapas ao vivo via satélite, fotos, vídeos, dentre tantas outras possibilidades, amplia nossa percepção do mundo e, ao abrirmos vários sites e programas ao mesmo tempo e inúmeros links e hiperlinks, nossa mente se acostuma com a grande e diversificada quantidade de informação disponível no mundo virtual.

Tudo isso coloca a definição de tecnologia em uma perspectiva bastante ampla. Podemos encontrar inúmeras definições para o termo, porém ele é tão vasto que nenhuma delas consegue determiná-lo por completo. De forma simplificada, podemos entender a tecnologia como a solução para um problema que visa à produção de conhecimento.

Como buscamos uma reflexão, cabe desde já enfatizar que a tecnologia não é boa, nem ruim, tampouco neutra. Uma vez que envolve relações humanas e sociais, a tecnologia é política, pois é uma maneira por meio da qual o homem modifica o seu ambiente e/ou a natureza para satisfazer suas necessidades e desejos; não se limitando, portanto, a produtos tangíveis. Daniel (2003) lembra que é importante nos atentar para o uso mais adequado das tecnologias, o que engloba não apenas as pessoas, mas também os sistemas sociais. Estes referem-se, por exemplo, ao acesso ou não de todos, à qualidade da tecnologia e seu custo, aspectos que estão ligados a questões políticas. Para Sancho e Hernández (2006),

As tecnologias da informação e comunicação não são neutras. Estão sendo desenvolvidas e utilizadas em um mundo cheio de valores e interesses que não favorecem toda a população. Além de considerar que um grande número de pessoas seguirá sem acesso às aplicações das TIC em um futuro próximo, devese lembrar que os processos gerados pela combinação dessas tecnologias e das práticas políticas e econômicas dominantes nem sempre são positivos para os indivíduos e a sociedade. (SANCHO; HERNÁNDEZ , 2006, p. 18)

As tecnologias, por si, não são responsáveis por mudanças drásticas na sociedade. O uso que fazemos delas é que é capaz de provocar tais mudanças. Moran 
(1995) afirma que as necessidades capitalistas impulsionam a difusão das tecnologias, pois elas são capazes de gerar mais lucro. Por isso, segundo o autor, "há interesse em ampliar o alcance da sua difusão, para poder atingir o maior número possível das pessoas economicamente produtivas, isto é, das que podem consumir” (MORAN, 1995, p. 1). Dentro dessa perspectiva, o pobre fica de fora do foco capitalista, longe do acesso. Menezes (2003) também comenta sobre essa questão ao asseverar que "o produto tecnológico nasce elitista, prospera, se massifica e termina o seu ciclo. Surge, então, um novo produto de base elitista, prospera [...]” (MENEZES, 2003, p. 2). O pobre nunca alcançará o rico no que diz respeito à tecnologia. Por outro lado, Menezes (2003) sugere que é a própria tecnologia que guia e direciona todas as mudanças na sociedade. Essa idéia carece de ressalvas, haja vista que é o uso que se faz da tecnologia o grande responsável pelas mudanças, ou seja, é o homem quem gerencia as mudanças que a tecnologia é capaz de propiciar.

A tecnologia pode transformar o ambiente em que vivemos em uma realidade que é construída artificialmente (MARTINEZ, 2006). Essa definição pode nos remeter ao mundo virtual, que é uma realidade construída artificialmente. No entanto, as comunidades ditas virtuais o são em que sentido? Por que não podemos dizer que são reais? De acordo com Moran (1995), vivemos um encantamento pelas tecnologias, uma vez que a interação entre o real e o virtual é muito intensa. Essa interação mais intensa é advinda das novas tecnologias. Mas o que são "novas” tecnologias?

Tendemos a associar novas tecnologias ao conceito de Novas Tecnologias da Informação e Comunicação (doravante NTIC), o qual se refere aos métodos e tecnologias que surgiram com a Revolução Informacional com o intuito de comunicação, principalmente a partir da década de 1990. De acordo com o site Wikipédia,

A imensa maioria delas se caracteriza por agilizar, horizontalizar e tornar menos palpável (fisicamente manipulável) o conteúdo da comunicação, por meio da digitalização e da comunicação em redes (mediada ou não por computadores) para a captação, transmissão e distribuição das informações (texto, imagem estática, vídeo e som).

Contudo, o conceito de novo é relativo. Seria interessante pensar na visão que as pessoas têm, por exemplo, a respeito do celular. Para os mais velhos, o telefone celular é uma nova tecnologia e muitos ainda o vêem com receio. Por outro lado, para os adolescentes pode parecer inconcebível um mundo sem o celular. Uma jovem atriz americana afirmou na televisão, há poucos meses, que não consegue imaginar como as pessoas viviam sem o celular: "O que vocês faziam quando queriam falar com alguém?”, ela questiona, bastante surpresa, quando o entrevistador diz que quando ele era jovem não havia celular. A questão do "novo" é de fato complicada, pois se algo existe há muito tempo, mas uma pessoa nunca o viu antes, ela pode considerar aquilo bastante novo, como demonstra a charge abaixo: 


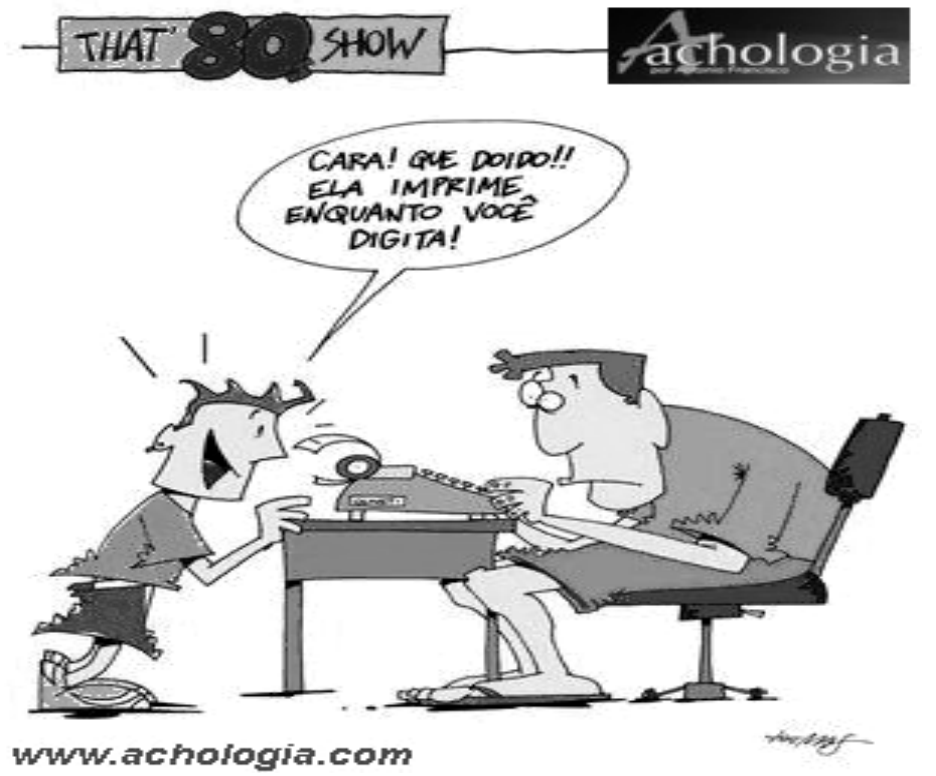

Figura 1: O que é o "novo”?

A figura acima é bastante ilustrativa da relatividade do termo "novo". As crianças, hoje, utilizam com bastante destreza os computadores e celulares de última geração, mas poderiam se surpreender ao ver uma máquina datilográfica sendo usada. Conforme Almeida (2007),

O novo não é uma propriedade da matéria, mas uma qualidade de consciência. Portanto, ele não reside em lugar algum, mas habita as consciências receptivas. Isto significa dizer que o novo é imaterial, não é o objeto que carrega consigo a novidade, mas o olhar de crescente consciência que percebe a diferença no novo e sempre antigo mundo material. (ALMEIDA, 2007, p. 1)

Belloni (2006) argumenta que as tecnologias antigas podem se renovar por meio de usos diferenciados que o ser humano lhes coloca, o que complica ainda mais a definição de "novas" tecnologias. Contudo, a autora consegue nos fornecer uma definição apropriada de NTIC, a qual será considerada neste trabalho quando, de agora em diante, mencionarmos novas tecnologias:

Correndo o risco de simplificar, podemos dizer que, nos tempos que correm, as NTICs são fundamentalmente aquelas - recheadas de informática - que permitem a estocagem e a transmissão de informações em quantidade, qualidade e velocidade inéditas na história da humanidade e que têm como característica essencial a "imaterialidade” de sua matéria-prima, a informação. (BELLONI, 2006, p. 65)

Se as NTIC se relacionam com a transmissão de grandes quantidades de informações com rapidez nunca antes vista, podemos dizer que a televisão, o vídeocassete e o rádio não são novas tecnologias, pois estão convergindo para outros recursos que utilizam o protocolo IP da Internet, assim como Martínez (2004) afirma. 
Segundo Miranda (2007), as NTIC são redundantes. Para ela, “a referência à novidade nada acrescenta à delimitação e clarificação do domínio. Mais ainda, o que é novo hoje deixa de o ser amanhã” (MIRANDA, 2007, p. 43). Assim, dois aspectos são relevantes: (1) as "novas” tecnologias nem sempre chegam para substituir as "velhas", mas podem ser utilizadas juntas para tentar resolver problemas, como, por exemplo, contribuir para o processo de ensino e aprendizagem; (2) as NTIC já estão postas e nos resta refletir sobre as melhores e mais adequadas maneiras de utilizá-las, principalmente os professores que trabalham com as crianças e jovens nascidos na era digital.

\section{A tecnologia na sala de aula}

A tecnologia educativa pode ser entendida como a aplicação da tecnologia para a melhoria do processo educacional. Vista desse modo, ela nada tem de novo. Os professores sempre utilizaram algum tipo de tecnologia visando à melhoria do processo de ensino e aprendizagem. No entanto, como Belloni (2006) afirma, as novas tecnologias transmitem informações em velocidades inimagináveis e seu impacto para a sociedade é muito maior. As mudanças são muito mais complexas, com a criação, por exemplo, dos mundos virtuais, os chamados ciberespaços.

Para Menezes (2003), todos nós devemos nos adequar a esses novos processos, pois eles são inevitáveis e irreversíveis. Assim, cada tecnologia afetará nossa interrelação com o ambiente em que vivemos, com o mundo e com as pessoas, afetará nossa percepção da realidade. O professor não se situa fora desse ambiente e, por essa razão, devemos pensar em melhores maneiras de inserir as "novas" tecnologias em sala de aula.

A tecnologia educativa surge como a aplicação das "novas" tecnologias nos processos relativos à educação. Na perspectiva de Miranda (2007), “o termo não se limita aos recursos técnicos usados no ensino, mas a todos os processos de concepção, desenvolvimento e avaliação da aprendizagem” (MIRANDA, 2007, p. 42). Segundo a autora, a tecnologia educativa envolve questões de gestão educacional, de desenvolvimento educacional e também os recursos de aprendizagem. Similar a Miranda (2007), Coutinho (2007) define a tecnologia educativa:

não como o simples uso de meios tecnológicos mais ou menos sofisticados, mas como uma forma sistemática de conceber, gerir e avaliar o processo de ensino e aprendizagem em função de metas e objetivos educacionais perfeitamente definidos. (COUTINHO, 2007, p. 1)

A própria sala de aula também pode ser vista como uma forma de tecnologia, uma vez que é uma ferramenta pedagógica que realiza a mediação entre o aluno e o conhecimento (BELLONI, 2006). A autora afirma que as NTIC devem ser consideradas como "ferramentas pedagógicas" e o professor deve entender seu uso não como uma forma de invenção técnica, mas uma forma de "imaginação pedagógica".

Moran (1995) caminha na mesma direção que Belloni (2006). Quase uma década antes desta autora, ele já dizia que o avanço da tecnologia traria motivos para que fiquemos tanto fascinados quanto alienados, o que traz a necessidade de sermos críticos. Para o autor, "nossa mente é a melhor tecnologia, infinitamente superior em 
complexidade ao melhor computador, porque pensa, relaciona, sente, intui e pode surpreender" (MORAN, 1995, p. 5). Segundo ele, devemos fazer uso libertador das tecnologias, e não consumista, usando nossas mentes e integrando nossos sentidos. Por isso, o uso que se faz da tecnologia é mais importante que a tecnologia em si, e o professor pode usar a sua mente criadora e criativa para surpreender e não apenas usar a tecnologia como um quadro e um giz modernos.

Nas salas de aula, há ainda professores que vêem as tecnologias com muito receio, com medo. Por outro lado, há os professores que acreditam que as tecnologias podem ser uma poção mágica que resolverá todos os problemas que eles enfrentam diariamente nas escolas. Na verdade, a tecnologia não deve ser temida, tampouco considerada mágica. O uso que fazemos da tecnologia é que pode modificar o processo de ensino e aprendizagem, nossas relações interpessoais e nossa sociedade. De acordo com Moran (1995),

As tecnologias de comunicação não mudam necessariamente a relação pedagógica. As tecnologias tanto servem para reforçar uma visão conservadora, individualista como uma visão progressista. A pessoa autoritária utilizará o computador para reforçar ainda mais o seu controle sobre os outros. Por outro lado, uma mente aberta, interativa, participativa encontrará nas tecnologias ferramentas maravilhosas de ampliar a interação. (MORAN, 1995, p. 5)

O uso das novas tecnologias na sala de aula não garante um processo de ensino e aprendizagem inovador, centrado no aluno e nas suas necessidades. O professor tradicional que gosta das aulas centradas em si mesmo, por exemplo, tenderá a utilizar as novas tecnologias para concentrar ainda mais o processo, enquanto o professor que reconhece a importância de mudanças na sala de aula terá mais facilidade para pensar em formas de utilizar as tecnologias para modificar o processo tradicional e conservador que ainda prevalece em várias escolas. Essa é a questão-chave para a tecnologia educativa: desenvolver novas metodologias para sua incorporação no processo de ensino e aprendizagem - o qual não envolve apenas o ambiente de sala de aula presencial, mas está muito além dele - de modo a educar os jovens de acordo com as exigências complexas da sociedade globalizada. A construção, organização e processamento do conhecimento precisam ser mais interativas, flexíveis e amplas. Para Coutinho (2007), o novo cenário mundial exige "uma abordagem holística do processo educacional que passa pela integração da tecnologia no currículo com vista a uma expansão do mesmo e a uma participação mais ativa dos alunos no processo de ensino/aprendizagem" (COUTINHO, 2007, p. 8).

Sobressai a idéia de tecnologia como conhecimento e possibilitadora de mudanças. Moran (1995) refere-se a um encantamento que depende de nós, da nossa capacidade de lidar com as tecnologias que nos são apresentadas, olhar para elas criticamente e, se as considerarmos adequadas, transformá-las em ferramentas pedagógicas para tornar as aulas centradas nos aprendizes, e fazer deles pessoas mais autônomas, co-responsáveis pela construção de seu próprio conhecimento, de seu próprio saber.

As tecnologias permitem diversos e variados usos e, para Moran (1995), o poder de encantamento e sedução está nisso. O professor deve utilizar sua "imaginação tecnológica” para transformar as NTIC em ferramentas pedagógicas, criando usos inovadores e até mesmo inesperados para elas. O uso das tecnologias não deve ser, pois, 
enfeite para a sala de aula, uma maneira de impressionar o aluno. Elas não devem visar à concepção tradicional de educação de acúmulo de conhecimento, mas a uma mudança de paradigma, que vise à aprendizagem de habilidades que a sociedade moderna exige de nós. Não se deseja memorizadores de informações, mas seres humanos capazes de revolver problemas, encontrar soluções diferentes para esses problemas, pessoas criativas, capazes de colaborar. Moreira e Kramer (2007) colocam ainda outras habilidades que os alunos devem desenvolver: coragem, lealdade, capacidade de resolver problemas e satisfazer-se com sucesso.

Sandholtz, Ringstaff e Dwyer (1997) comentam sobre um projeto de implementação das tecnologias na sala de aula e reconhecem as dificuldades enfrentadas pelos professores, e enfatizam também que a tecnologia não tem papel mágico. Conforme os autores, a contribuição da tecnologia sofreu interferências humanas, educacionais e das organizações. As pessoas perceberam que "A tecnologia, em si, não era a bala de prata” (SANDHOLTZ; RINGSTAFF; DWYER, 1997, p. 48). Os professores, que já tinham uma carga de trabalho pesada, teriam ainda outras questões para administrar. Contudo, os autores afirmam que o projeto continuou e os professores encontraram formas de utilizar a tecnologia. Assim, a mudança de uso das tecnologias ocorreu a partir da mudança nas crenças dos professores.

Destacamos, novamente, a importância do uso que o professor faz das tecnologias e de sua maneira de ver o ambiente de sala de aula, ou melhor, suas crenças com relação às abordagens de ensino e aprendizagem. Mudar crenças não é simples, é preciso, primeiramente, tomar consciência de suas próprias crenças - o que por si já é bastante complexo - e, depois, pensar reflexivamente sobre elas para, então, passar por repetidos esforços para se chegar a mudanças.

Vimos que nossa mente é mais criativa e complexa que qualquer computador e é ela que leva ao uso inovador e inesperado das tecnologias. Miranda (2007) também pontua que as tecnologias só trazem melhorias para o processo de ensino e aprendizagem se os professores de fato acreditarem e estiverem dispostos a dispensar esforços para desenvolver "actividades desafiadoras e criativas, que explorem ao máximo as possibilidades oferecidas pelas tecnologias” (MIRANDA, 2007, p. 44).

Considerar as tecnologias como miraculosas é um fator também discutido por Moreira e Kramer (2007). Para eles, quando as pessoas acreditam que as tecnologias funcionam como condões mágicos que solucionarão todos os problemas educacionais, a qualidade da educação passa a ser vista como o uso dos recursos tecnológicos, seja ele eficiente e criativo ou não. Acreditamos que isso pode levar a uma sala de aula que não seja nem teacher-centered, nem student-centered, mas technology-centered, o que seria ainda pior, uma vez que retira o ser humano do centro e coloca a tecnologia como principal ator na sala de aula, um local que deve ser fonte de interação entre as pessoas para a construção de um conhecimento sólido. As habilidades cognitivas das crianças são determinadas a partir da interação, como afirmou Vygotsky (1991).

O uso das tecnologias requer visão crítica por parte de todos os envolvidos com os processos escolares, pois a utilização dessas tecnologias deve ser apropriada às necessidades dos alunos. Eles devem tornar-se mais autônomos e participativos do processo educacional e empenhar-se na mudança de seu ambiente.

As tecnologias, de fato, não são miraculosas. Elas não são capazes, por exemplo, de fazer desaparecer diferenças, desigualdades e divergências. Pelo contrário, podem até ampliá-las e torná-las mais evidentes pelo fato de terem um custo elevado e não serem 
de fácil acesso para todos. Dwyer et al. (2007) afirmam que "a sociologia da educação demonstra que as escolas, em vez de serem instituições de mobilidade social, são instituições de reprodução de desigualdades!” (DWYER et al., 2007, p. 1304)

Portanto, quando se fala em enfrentar os problemas da educação, a tecnologia educativa pode ajudar, mas o que se deve pensar, em primeiro lugar, é na educação e nas necessidades do aluno, e não na tecnologia em si. Quem faz a diferença é o homem e o uso que ele faz das tecnologias. Um problema que Daniel (2003) apresenta é que as tecnologias, em geral, são desenvolvidas para resolver um determinado problema que o homem enfrenta. Por exemplo, se o homem começa a sentir muito calor e isso o incomoda muito, ele utiliza o seu saber e desenvolve uma nova tecnologia, como o arcondicionado. O problema é que o mesmo não ocorre no caso da tecnologia educativa. Com isso em mente, ele afirma que "Antes de admitir que a tecnologia é a resposta, devemos indagar a que pergunta ela responde” (DANIEL, 2003, p. 1).

Mais importante que utilizar a tecnologia em sala de aula é saber utilizá-la para melhorar o processo de ensino e aprendizagem e modificar as posturas tradicionais de se pensar em educação. $\mathrm{O}$ foco deve estar nas necessidades do aluno. $\mathrm{O}$ que esse aluno precisa para resolver o seu problema? Conforme Bianchetti e Ferreira (2004), “a simples existência das TIC não garante um processo pedagógico mais rico e desafiador. É possível continuar tradicional mesmo usando as novas tecnologias" (BIANCHETTI; FERREIRA, 2004, p. 153).

Martínez (2004) também alerta para a não idolatria das novas tecnologias. Assim como Moreira e Kramer (2007), ele assevera que as tecnologias não acabam com as diferenças sociais, mas são capazes de melhorar outros problemas relativos à educação. Segundo o autor, as novas tecnologias não acabarão com os problemas enfrentados pela educação, mas elas podem contribuir para melhorar o processo.

Podemos perceber que as novas tecnologias não transformarão radicalmente as condições de ensino e aprendizagem, porém elas orientam o processo para uma abordagem mais centrada no aprendiz, ao possibilitar a construção de um conhecimento coletivo. Quando o aluno participa do processo de construção do conhecimento, em vez de apenas acumular "conhecimentos", ele é capaz de se apropriar daquilo que foi aprendido e torná-lo apreendido (FREIRE, 1977). Mesmo porque o acúmulo de grandes quantidades de informação não significa que o aprendiz vá transformar toda essa informação em conhecimento.

O novo paradigma pode assustar o professor, pois ele terá de abandonar o seu papel controlador. Ele não será aquele que tudo domina, que tudo sabe e que transmite os conhecimentos que possui. O papel do professor passa a ser de intermediador entre o conhecimento e os aprendizes, colocando-se em um patamar mais igualitário ao do aprendiz, com ele dialogando e interagindo para a construção do conhecimento.

Para Vygotsky (1991), a aprendizagem é um processo social, que ocorre a partir da interação dos aprendizes com o outro e com seu ambiente de convívio. Lévy (1993) compartilha a idéia de Vygotsky (1991) e de Freire (1977) e afirma que "quanto mais uma pessoa participar da aquisição de um conhecimento, mais ela irá integrar-se e reter aquilo que aprender” (LÉVY, 1993, p. 40).

As novas tecnologias podem proporcionar essa maior interação por parte do aprendiz, exigindo dele maior participação, criticidade, criatividade e autonomia. Isso está estreitamente relacionado com a definição de tecnologia de Chaves (1999), segundo a qual as tecnologias servem para expandir a mente. Por outro lado, o papel do professor 
não é diminuído, mas apenas modificado, ele também ampliará sua capacidade mental. O professor tem importantes funções, como, por exemplo, orientar seus aprendizes a sintetizar todas as informações que obtêm da Internet, analisá-las criticamente e mostrar caminhos para a busca do conhecimento desejado, além de planejar e desenvolver um projeto pedagógico que envolva a utilização das tecnologias para a melhoria do processo de ensino e aprendizagem.

Finalmente, é importante considerar a não linearidade na construção do conhecimento a que as novas tecnologias levam. A utilização de hiperlinks possibilita que o conhecimento seja construído a partir de uma “confusão” organizada. Derruba-se o lema positivista de "ordem e progresso”. Não é necessária a ordem linear, hierárquica e sistematizada dos conteúdos para que o aprendiz tenha progresso. Os hiperlinks conduzem o aprendiz a vários saberes, várias informações que, ao final de um processo, formarão um cidadão mais preparado para o mundo globalizado, informatizado e complexo em que vivemos.

\section{O caso de um blog em sala de aula de língua inglesa}

A partir dos esclarecimentos acerca dos conceitos de tecnologia, novas tecnologias e tecnologia educativa, pretendemos, neste item, refletir sobre o caso de uso de um blog em uma sala de aula de língua inglesa. As crenças dos alunos e da professora acerca do processo de ensino e aprendizagem de língua inglesa eram o foco do trabalho. Embora não fosse a questão central da pesquisa, o tema tecnologia surgiu durante a coleta de dados, provavelmente porque foi criado um blog para a turma, voltado, essencialmente, para atividades de compreensão auditiva, habilidade esta que os alunos sentiam a necessidade de aprimorar e pediram, no início do semestre, para que tivessem a oportunidade de fazer atividades que ajudassem a desenvolvê-la.

\section{A turma}

A turma era composta por 13 alunos, entre 19 e 25 anos, com exceção de um aluno de 33 anos. Todos eles, exceto este último, eram estudantes universitários de uma universidade federal do estado de Minas Gerais, dos seguintes cursos: ciência da computação, engenharia elétrica, engenharia química, agronomia, biomedicina e ciências biológicas. Nenhum deles havia utilizado um blog voltado para a aprendizagem. Um dos alunos nunca tinha ouvido falar em blog. Alguns não sabiam como utilizá-lo. Foi necessário mostrar, em sala de aula, o funcionamento do mesmo e tirar dúvidas dos alunos ao longo do semestre.

\section{A professora}

A professora tem 32 anos e trabalha com ensino de línguas há cerca de 10 anos. No que diz respeito à tecnologia, ela não faz parte da geração digital. Durante sua infância, não teve contato com computadores; o equipamento tecnológico mais marcante de sua época era uma máquina de datilografar. O grande avanço tecnológico que vivenciou enquanto aprendiz ocorreu no fim de sua adolescência com o advento da 
máquina datilográfica elétrica. Porém, naquela época, já começava a se popularizar o uso do computador.

Cerca de três meses antes do início das aulas, a professora participou de um curso online sobre o uso de blogs para o ensino e aprendizagem de línguas. Foi o seu primeiro curso online e seu primeiro contato com um blog. Durante o curso, a professora afirmou que percebeu o potencial dessa ferramenta e decidiu que iria propor a criação de um blog para a turma, porém ela não sabia ao certo qual seria o formato e o objetivo principal do blog até que os alunos mostraram seu anseio pelo desenvolvimento da habilidade auditiva.

\section{A diferença de gerações}

Aprendizes e professora pertencem a gerações diferentes, especialmente no que concerne à tecnologia. Prensky (2001) utiliza os termos Nativos Digitais e Imigrantes Digitais para ressaltar a diferença entre aqueles que, como a professora, não nasceram em um mundo digital, e a geração dos aprendizes, que são "falantes nativos da linguagem digital dos computadores, vídeo games e Internet” (PRENSKY, 2001, p. 1). A professora acreditava que seus alunos teriam muita facilidade com o computador, a internet e o blog, enquanto ela teria um pouco mais de dificuldade. No entanto, isso não se confirmou, com exceção de alguns casos de alunos que cursavam Ciência da Computação e já trabalhavam na área.

No Brasil, ser “nativo digital” parece também envolver questões de ordem econômica. Alunos com poder aquisitivo maior se enquadram na definição de Prensky (2001). Por outro lado, aqueles que vêm de classes mais baixas, apesar de ter conhecimento, não têm muito acesso, o que dificulta ser um "falante nativo da linguagem digital”.

\section{A metodologia}

Trata-se de uma pesquisa qualitativa com base na perspectiva Qualitativa Epistemológica, a qual entende que o conhecimento possui um caráter construtivointerpretativo. Dentro da Epistemologia Qualitativa, faremos uma interpretação da realidade para construir um conhecimento, o qual fica aberto para os questionamentos dos leitores, para que possam refletir sobre idéias aqui propostas, concordar com elas ou não, visando a colaborar para a (re)construção desse conhecimento.

Dentro dessa perspectiva, González Rey (2005) afirma que:

A Epistemologia Qualitativa defende o caráter construtivo interpretativo do conhecimento, o que de fato implica compreender o conhecimento como produção e não como apropriação linear de uma realidade que se nos apresenta. A realidade é um domínio infinito de campos inter-relacionados independente de nossas práticas; no entanto, quando nos aproximamos desse complexo sistema por meio de nossas práticas, as quais, neste caso, concernem à pesquisa científica, formamos um novo campo de realidade em que as práticas são inseparáveis dos aspectos sensíveis dessa realidade. São precisamente esses os aspectos sensíveis de serem significados em nossa pesquisa. (GONZÁLEZ REY, 2005, p. 5, grifo do autor) 
Para a coleta de dados, os aprendizes completaram um questionário aberto ao final do semestre e a professora mantinha um diário reflexivo, no qual registrava os eventos ocorridos em sala de aula, suas reflexões, desejos e problemas encontrados ao longo do desenvolvimento do projeto. A seguir, analisaremos a experiência dos participantes.

\section{A experiência do blog}

A idéia do blog surgiu de uma necessidade dos aprendizes de melhorarem a compreensão auditiva em língua inglesa, bem como criar possibilidades para que os aprendizes pudessem ter maior autonomia e maior contato com a língua-alvo. Vale ressaltar que as atividades feitas no blog não tinham caráter avaliativo. Foram distribuídos 5 pontos extras para todos aqueles que postassem seus comentários, independentemente de como fossem suas respostas para as atividades propostas. Concordamos com a afirmação de Prensky (2001) quando ele afirma que os Nativos Digitais estão acostumados a receber informações rapidamente, preferem acessos randômicos, adoram gratificações instantâneas e preferem jogos a trabalho "sério" (PRENSKY, 2001, p. 2).

Assim, ao iniciar o curso, a professora acreditava que praticamente todos os alunos teriam acesso fácil à Internet e fossem participar ativamente das atividades propostas no blog, mesmo porque todas tinham caráter mais divertido e menos sério, e os alunos seriam "nativos digitais". No diário reflexivo, ela escreveu:

"Ao final da aula, sugeri a eles a criação de um blog da turma, o qual pretendo que tenha mais atividades divertidas, que não pareça um homework normal. $O$ objetivo também é trabalhar com listening, pois quase todos os alunos já vieram a mim falar sobre suas dificuldades com essa habilidade e seu desejo de melhorar.

Eles aceitaram, mas estão com receio de ter que fazer muitas atividades extras. Estão com receio. Nenhum aluno utilizou blog antes para aprendizagem, e um deles perguntou o que era um blog. Achei que ele estivesse brincando, mas de fato ele não tinha nem idéia do que fosse.

Quais são as minhas expectativas? Afinal, é também a primeira vez que eu trabalharei com blog. Eu espero que eles se divirtam, que seja um espaço no qual eles possam ser mais independentes e autônomos e, principalmente, um espaço diferente daquilo que eles já conhecem: a sala de aula. Espero muita interação entre os alunos e comigo também. E acredito que eles possam aprender bastante. Como muitos deles já me pediram ajuda para melhorar o listening, pretendo colocar "atividades" que eles poderão utilizar para desenvolver essa habilidade”.

O trecho acima explicita as intenções e expectativas iniciais da professora. No entanto, muitas dessas expectativas não se concretizaram. Embora os alunos tivessem acesso à Internet, isso acontecia, na grande maioria dos casos, por meio dos computadores da própria universidade, os quais não dispunham de caixas de som ou fones de ouvido. Isso foi um grande problema, pois todas as atividades propostas, exceto uma, necessitavam de áudio, ou áudio e vídeo. Alguns aprendizes deixavam 
passar algumas semanas e iam a uma Lan House para fazer as atividades do mês, que poderiam ser 3 ou 4 . Outros sequer conseguiram participar de qualquer atividade do blog, embora fossem alunos participativos na sala de aula. Duas alunas que tinham esse problema afirmaram no questionário aberto final:

"Eu imaginava que o blog seria mais fácil. O blog foi útil para alguns, mas para mim que só fiz duas partes, não ajudou muito”.

"Eu imaginava que o blog seria uma atividade sem graça. $O$ blog foi muito legal, mas eu não tive muito tempo para aproveitar”.

As falas acima exemplificam o caso de aprendizes que, apesar de pensarem que o blog pudesse ser útil ou interessante, não tiveram oportunidade de aproveitar o suficiente dessa ferramenta devido à dificuldade de acesso.

Houve também casos, principalmente no início do semestre, de alunos que não sabiam como utilizar o blog. Eles, apesar de serem, teoricamente, Nativos Digitais, não dominavam aquela linguagem e, com isso, apenas assistiam aos vídeos, por exemplo, e não sabiam como fazer a atividade proposta pela professora, mesmo com as instruções fornecidas em sala de aula para demonstrar como eles poderiam utilizar o blog. Alguns aprendizes chegavam à sala de aula e queriam explicar para a professora o que haviam feito e descreviam o vídeo para garantir à professora que tinham desenvolvido a atividade.

Outro problema foi a vergonha que alguns aprendizes sentiram de se expor, pois todos os colegas poderiam ler o seus comentários e/ou respostas. Houve casos de alunos que traziam as atividades feitas em uma folha de papel e mostravam para a professora 0 que tinham feito, contavam o que haviam entendido e faziam perguntas quando tinham dificuldades, mas não escreviam nenhum comentário. Eles utilizaram o blog, essa "nova" ferramenta digital, de modo tradicional. Assim, a tentativa de se ter uma sala de aula virtual por meio do blog não foi muito bem-sucedida.

A professora acreditava e esperava que os alunos iriam interagir mais no ambiente digital e tentou incentivá-los a fazer referência aos comentários dos colegas, a tentar oferecer sugestões uns aos outros. Porém, a interação ficou bastante aquém do esperado e quem, por fim, acabou fazendo quase toda a interação foi a própria professora. Assim, a interação ficou um pouco centrada na professora, com exceção de alguns casos em que os alunos concordavam com um colega, por exemplo. Ao perceber o que estava ocorrendo, a professora tentou se limitar a "conversar" com os aprendizes. Ela não mais dizia se algo estava certo ou errado. Ela passou a comentar o que os aprendizes haviam escrito na tentativa de dar o exemplo de como eles poderiam interagir uns com os outros, mas poucos foram os alunos que tentavam a interação. É o que mostra o trecho seguinte do diário reflexivo.

“[...] no blog, há pouca interação. Na verdade, poucos alunos entram com a freqüência desejada. Eu me vejo, então, na posição de fazer essa interação com os poucos alunos que postam seus comentários para que eles não fiquem "no vão”. Há problemas com relação ao acesso: a maioria dos alunos não tem computador em casa, os computadores a que eles têm acesso na universidade não têm som e as atividades todas precisam de som. 
Eu achava que todos, ou a maioria, teriam computador, mesmo porque muitos fazem engenharia ou computação, mas a realidade é diferente. O computador ainda não é um bem de fácil acesso.

Outro problema com relação ao blog, é que às vezes, o aluno fica com vergonha de escrever, pois os colegas vão ver. 3 alunos me disseram hoje que assistiram ao vídeo postado, mas não fizeram a atividade e nem deixaram um comentário. Sei de fato que eles assistiram mesmo, pois contaram como foi”.

Muitas das expectativas da professora não se realizaram. Ao longo do semestre, ocorrem problemas que ela não havia antecipado, provavelmente por nunca ter utilizado um blog no ensino e aprendizagem de inglês antes. A professora também não imaginava que, ainda hoje, o acesso à internet com qualidade não é privilégio de todos. Os aprendizes, por sua vez, por não terem o costume com a ferramenta, não sabiam ao certo como proceder e demonstraram vergonha de se expor na rede e interagir com os colegas.

Um dos alunos que realizou todas as atividades propostas no blog escreveu no questionário aberto final a respeito da interação:

"Eu imaginava que o blog seria uma forma de interação entre os alunos e uma forma de ter exercícios extras. $O$ blog foi uma forma de termos exercícios extras e praticar listening".

Percebe-se na sua fala que ele também esperava uma interação maior com os colegas, mas isso não aconteceu e serviu-lhe apenas como atividade extraclasse.

Apesar de estarmos de acordo com algumas idéias de Prensky (2001), acreditamos que, no que tange à situação do Brasil, não podemos nos esquecer de outros problemas além daqueles que se referem às diferenças entre as gerações e à necessidade de desenvolvermos novas metodologias de ensino que levem em consideração que os alunos de hoje são diferentes dos alunos de alguns anos atrás. Logo, devemos anuir com Daniel (2003) quando ele afirma que "Hoje as pessoas comuns e os governos têm muitas preocupações a respeito da educação, e elas se resumem a três problemas mais importantes. O primeiro é o acesso, o segundo a qualidade, o terceiro o custo" (DANIEL, 2003, p. 2).

Esses são problemas que, de fato, devemos considerar. Antes de pensar em novas metodologias, em quais tecnologias utilizar e em como estimular os nossos alunos, é necessário que eles tenham acesso de qualidade, a um custo baixo. Os problemas colocados por Daniel (2003) foram os principais a afetar, de modo negativo, a experiência do blog nesse contexto de ensino e aprendizagem de língua inglesa.

Contudo, é relevante visualizar o uso da tecnologia sob uma perspectiva mais ampla. As metodologias de trabalho com as novas tecnologias precisam ser desenvolvidas. Não basta preparar uma apresentação em Powerpoint e ler o que está escrito nela para os alunos e esperar que eles copiem. Isso seria apenas um quadro negro diferente, seria transpor uma metodologia tradicional para o mundo virtual.

Outra questão é pensar na necessidade dos aprendizes. Daniel (2003) cita o caso de mulheres da Universidade Aberta da Tanzânia. Quando perguntadas sobre suas opiniões acerca do uso da tecnologia para melhorar a aprendizagem, elas afirmaram que necessitavam de fogões, aspiradores, máquinas de lavar, para que pudessem gastar 
menos tempo nos afazeres domésticos e mais tempo estudando. Neste estudo, a necessidade dos aprendizes foi relevante para a criação do blog, o qual se voltou para atividades de compreensão auditiva, que constituíam o desejo e as necessidades relatadas pelos aprendizes.

Por fim, o depoimento de um aluno que nos fez refletir não apenas sobre as necessidades dos alunos, mas também a maior participação deles no processo:

"Eu imaginava que o blog seria [...] foi como eu imaginei, porém acho que se pudéssemos colocar algumas coisas, vídeos, textos seria melhor”.

Isso mostra que esse aluno gostaria de ter mais autonomia para participar mais ativamente do processo, o que o blog não permitiu, pois apenas a professora postava os vídeos e coube aos aprendizes apenas colocar comentários, ou responder às perguntas. Talvez uma wiki seria mais interessante que um blog. A professora refletiu a esse respeito e afirmou que talvez a sua falta de experiência com o uso do blog para o processo de ensino e aprendizagem possa também ter tido influência nos problemas que encontramos com essa experiência. Contudo, é necessário começar por algum lugar e não apenas se conformar com a situação, ou temer a mudança justamente por receio de não conseguir. A professora dedicou-se ao projeto e às necessidades dos aprendizes e não teve medo de tentar o novo. A partir dessa experiência, ela deseja continuar a testar as possibilidades que surgirem com blogs e wikis e continuar fazendo o possível para mudar o paradigma tradicional que ainda permeia a educação, pois como Charles Darwin afirmou, "Não é a espécie mais forte que sobrevive, nem a mais inteligente, mas sim aquela mais receptiva a mudanças". ${ }^{1}$

\section{Considerações finais}

No atual momento do desenvolvimento tecnológico, não cabe mais a questão de ter medo das novas tecnologias, nem idolatrá-las. A tecnologia educativa já está posta e não há como recuar. O importante é buscar novos conhecimentos, melhor formação, para, então, refletir sobre possíveis formas de utilizar as NTIC no processo de ensino e aprendizagem. Algumas tentativas serão positivas, outras nem tanto. Porém, a tentativa em si já pode levar a resultados melhores que a inércia.

Acreditamos que esta experiência de utilização do blog tenha sido válida, apesar das dificuldades encontradas por alguns aprendizes, bem como pela professora. Com o tempo, eles podem se dar conta de como deveria ser o seu papel nessa "diferente" forma de aprender e ensinar. A professora, ao final da experiência, mostrou-se ciente das possíveis dificuldades que os alunos podem apresentar e parece ser capaz de tentar driblar algumas delas, ou mesmo discutir as possibilidades de melhoria de acesso de qualidade aos estudantes dentro da universidade. Além disso, ela se propõe a pensar em outras formas de tornar a participação dos aprendizes mais ativa, considerando que um deles mesmo afirmou que gostaria de poder postar atividades também. Como poderíamos fazer isso, mesmo em um blog? Talvez abrindo uma conta em que todos os

\footnotetext{
${ }^{1}$ Texto original: It's not the strongest of the species that survives, nor the most intelligent, but the one most responsive to change.
} 
alunos tivessem acesso irrestrito. A professora afirmou que essa seria a próxima experiência que gostaria de vivenciar.

Por fim, é relevante lembrar que, no caso do Brasil, há que se buscar novos investimentos. Nem todos os jovens são nativos digitais pela falta de acesso a uma tecnologia de qualidade. Não basta colocar as NTIC nas salas de aula de todas as escolas, mas sim buscar novas metodologias de ensino e aprendizagem. A professora deste estudo sentiu falta dessas metodologias e desenvolveu um trabalho de tentativas e erros para tentar descobrir uma metodologia. Há que se admitir que os papéis de todos os envolvidos com o processo de ensino e aprendizagem devem mudar para se adequar às novas exigências da sociedade atual. Acreditamos que o primeiro passo para o uso das novas tecnologias seja: aceitar, buscar e refletir; tentar, errar, e refletir; colaborar e refletir.

\section{Referências}

ALMEIDA, Guilherme Assis de. Novo milênio novo de novo. 2007. Disponível em: http://www.mundodosfilosofos.com.br/guilherme15.htm . Acesso em: 10 maio 2008.

BELLONI, Maria Luiza. Educação à distância. 4. ed. Campinas, SP: Autores Associados, 2006. p. 53-77. (Coleção educação contemporânea).

BIANCHETTI, Lucídio; FERREIRA, Simone de Lucena. As tecnologias de informação e de comunicação e as possibilidades de interatividade para a educação. Revista FAEEBA. Salvador, v. 13, n. 22, 2004.

BUCHSBAUM, André; BUCHSBAUM, Paulo (Org.). Do bestial ao genial: frases da política. Rio de Janeiro: Ediouro, 2006.

CHAVES, Eduardo O. C. Tecnologia na educação: conceitos básicos. 1999. Disponível em: http://edutec.net/Tecnologia\%20e\%20Educacao/edconc.htm . Acesso em: 10 maio 2008.

COUTINHO, Clara Pereira. Tecnologia educativa e currículo: caminhos que se cruzam ou se bifurcam? Revista Teias, v. 8, n. 15-16, jan./dez, 2007. Disponível em: http://www.revistateias.proped.pro.br/index.php/revistateias/article/view/176/174 . Acesso em: 23 maio 2008.

DANIEL, John. Tecnologia é a resposta: qual é a pergunta? - A importância das novas tecnologias educacionais para a formação de professores para a educação básica. Palestra apresentada no Fórum Brasil de Educação - $3^{\circ}$ Encontro Nacional. 2003. Disponível em: http://portal.unesco.org/education/en/ev.phpURL_ID=19398\&URL_DO=DO_TOPIC\&URL_SECTION=201.html . Acesso em: 2 jun. 2008.

DWYER, Tom; WAINER, Jacques; DUTRA, Rodrigo; COVIC, André; MAGALHÃES, Valdo; FERREIRA, Luiz Renato; PIMENTA, Valdiney Alves; 
CLAUDIO, Kleucio. Desvendando mitos: os computadores e o desempenho no sistema escolar. Revista Educação e Sociedade. Campinas, v. 28, n. 101, p. 1303-1328, set./out, 2007. Disponível em: http://www.cedes.unicamp.br . Acesso em: 28 maio 2008.

GARDNER, Howard. Cinco mentes para o futuro. São Paulo: Artmed, 2007. p. 11-26.

LÉVY, Pierre. As tecnologias da inteligência: o futuro do pensamento na era da informática. Rio de Janeiro: Editora 34, 1993.

A inteligência coletiva: por uma antropologia do ciberespaço. São Paulo: Loyola, 1998. p. 47-58; p. 103-111.

MARTÍNEZ, Jorge H. Gutiérrez. Novas tecnologias e o desafio da educação. In: TEDESCO, Juan Carlos (Org.). Educação e novas tecnologias: esperança ou incerteza? São Paulo: Cortez; Buenos Aires: Instituto Internacional de Planeamiento de la Educacion; Brasília: UNESCO, 2004. p. 95-108.

MARTINEZ, Vinício Carrilho. Conceito de tecnologia. 2006. Disponível em: http://www.gobiernoelectronico.org/node/4652 . Acesso em: 2 jun. 2008.

MENEZES, Eduardo Pimentel. Novas tecnologias: repercussões no tempo e no espaço da educação a distância. 2003. Disponível em: http://www.abed.org.br/seminario2003/texto07.htm>. Acesso em: 14 maio 2008.

MIRANDA, Guilhermina Lobato. Limites e possibilidades das TIC na educação. Sísifo Revista de Ciências da Educação. Lisboa, n. 3, maio/ago., 2007, p. 41-50. Disponível em: http://sisifo.fpce.ul.pt . Acesso em: 05 abr. 2008.

MORAN, José Manuel. Novas tecnologias e o re-encantamento do mundo. Revista Tecnologia Educacional. Rio de Janeiro, v. 23, n. 126, set-out, p. 24-26, 1995. Disponível em: http://www.eca.usp.br/prof/moran/novtec.htm . Acesso em: 5 abr. 2008.

MOREIRA, Antonio; KRAMER, Sonia. Contemporaneidade, educação e tecnologia. Revista Educação e Sociedade. Campinas, v. 28, n. 100 (edição especial), p. 1037-1057, out., 2007. Disponível em: http://www.cedes.unicamp.br . Acesso em: 5 abr. 2008.

NUNES, Marília Forgearini. O papel do supervisor frente às novas tecnologias, 2007. Disponível em: http://www.centrorefeducacional.com.br/supertec.htm . Acesso em: 14 maio 2008.

PRENSKY, Marc. Digital Natives, Digital Immigrants. On the Horizon. MCB University Press, v. 9, n. 5, out., 2001. Disponível em: www.marcprensky.com/writing/default.asp . Acesso em: 17 jun. 2008.

SANCHO, Juana Maria; HERNÁNDEZ, Fernando. Tecnologias para transformar a educação. Tradução de Valério Campos. Porto Alegre: Artmed, 2006. p. 15-41. 
SANDHOLTZ, Judith Haymore; RINGSTAFF, Cathy; DWYER, David. Ensinando com tecnologia: criando salas de aula centradas nos alunos. Porto Alegre: Artes Médicas, 1997. p. 47-63.

VYGOTSKY, Lev Semenovictch. A formação social da mente: o desenvolvimento dos processos psicológicos superiores. São Paulo: Martins Fontes, 1991. 